Revista Herencia Vol. 29 (1), 21-32, 2016

Recibido 12-11-2015 Aprobado 15-12-2015

\title{
SIN MIEDO A VERSE EN EL ESPEJO: EL DOCUMENTAL FOLK COMO PRESERVADOR DEL PATRIMONIO CULTURAL INMATERIAL EN COSTA RICA
}

\section{Lorna Chacón Martínez. \\ Periodista con experiencia en medios de comunicación costarricenses e internaciona- les por más de 20 años. Posee una Maestría en Administra- ción de Empresas, con énfasis en medios de comunicación y una Maestría en Diseño de Lenguaje Audiovisual y \\ Multimedia. Es profesora, investigadora y coordinadora de la Comisión de Docencia en la Escuela de Ciencias de Comunicación Colectiva de la Universidad de Costa Rica. Actualmente es directora de dicha escuela. lorna.chacon@ gmail.com}

Juan José Muñoz Knudsen. Graduado en Ciencias de la Comunicación Colectiva con énfasis en Periodismo de la Universidad de Costa Rica. Ha trabajado en distintos proyectos culturales, principalmente literarios.

Posee una Maestría en Diseño de Lenguaje Audiovisual y Multimedia. Editó la Revista Voz UCR y en el 2015 fundó la editorial "Feliz Feliz" con la que publicó su primer libro "Genial 2006". jjmk90@ gmail.com

\section{Resumen}

El presente artículo reflexiona acerca del documental en Costa Rica como una vía para el resguardo en imágenes del patrimonio cultural inmaterial del país. Plantea una propuesta de definición para este tipo de audiovisual, denominado Documental Folk, el cual refleja la identidad de una nación que ahora muestra sus múltiples rostros gracias a la narrativa digital y al papel de los prosumidores.

Palabras clave: Documental, Patrimonio Intangible, Comunicación, Narrativa Digital, Identidad.

\section{Abstract}

This article reflect on the documentary in Costa Rica like a way to preserve with images the National patrimony. Propose the definition for this audiovisual, called Folk Documentary, which reflect the nation's identity with several faces thank to the Digital storytelling and the rol of prosumers.

Key Words: Documentary, Intangible Patrimony, Communication, Digital Storytelling, Identity.

\section{El audiovisual: el poder de ver lo intangible}

A lo largo de la historia, las prácticas y expresiones culturales de un país se han heredado de generación en generación de forma oral y escrita. Sin embargo, en los últimos años, el acceso y el abaratamiento de las tecnologías de la información y la comunicación han permitido registrar en mayores proporciones todo ese patrimonio inmaterial de una forma tangible: por medio de las imágenes del lenguaje audiovisual.

El patrimonio cultural inmaterial o intangible de un país se refiere a "las tradiciones y expresiones orales, incluido el idioma como vehículo del patrimonio cultural inmaterial, las artes del espectáculo, los usos sociales, rituales y actos festivos, los conocimientos y usos relacionados con la naturaleza y el universo y las técnicas ancestrales tradicionales", de acuerdo con la definición de la Organización de Naciones Unidas para la Educación, la Ciencia y la Cultura -UNESCO(2014: p.1).

Por lo anterior, en este artículo nos hemos planteado las siguientes preguntas: ¿Qué elementos del patrimonio cultural inmaterial son representados en las producciones documentales costarricenses? ¿Quiénes son los realizadores de estos 
documentales audiovisuales? ¿Qué temáticas abordan en sus documentales y por qué lo hacen?

Estas preguntas se relacionan con una necesidad de comunicación existente en el país: Costa Rica no cuenta con una Cinemateca o una Medioteca que sistematice y clasifique los documentales que se producen por lo tanto, y al igual que el resto de producciones audiovisuales, están archivados en distintas instituciones, por medio de diversos formatos y con diferentes metodologías. Además, muchos de ellos solamente se divulgan mediante la red Internet, donde también se encuentran fragmentados y sin estándares unificados de archivo, lo que dificulta aún más su búsqueda y clasificación.

Es por ello que hemos indagado sobre los documentales que abordan temáticas del patrimonio cultural inmaterial producidos en Costa Rica durante un periodo de cinco años (2009-2013), tanto de forma profesional como aficionada, para poder analizarlos y sistematizarlos en categorías que nos permitan entender mejor cómo se ven a sí mismos los "ticos" a través de las imágenes.

Para elaborar este artículo, revisamos los documentales producidos en el periodo mencionado por realizadores profesionales y que se encuentran archivados en las siguientes instituciones: Centro Costarricense de Producción Cinematográfica del Ministerio de Cultura y Juventud, Escuela de Ciencias de la Comunicación Colectiva de la Universidad de Costa Rica, Nueva Escuela de Cine y Televisión de la Universidad Veritas, Centro de Patrimonio del Ministerio de Cultura y Juventud, Canal UCR (Canal 15) de la Universidad de Costa Rica, Canal 13 (del Sistema Nacional de Radio y Televisión) y el Programa de Producción de Materiales Audiovisuales de la Universidad Estatal a Distancia (UNED).

Asimismo, escogimos la red social en línea Youtube para buscar los documentales realizados en ese mismo periodo por personas aficionadas pero también por personas con preparación profesional en el área audiovisual bajo las siguientes palabras clave: Costa Rica-Audiovisual, Costa Rica-Patrimonio, Costa Rica-Documental y Costa Rica-Tradiciones.

Además, decidimos dejar una categoría en línea abierta, a la que hemos denominado "Gallo Pinto", en la cual se contemplan documentales que no responden a una clasificación específica por palabras clave, pero que surgieron durante la búsqueda para la realización de este artículo y poseen un contenido sumamente valioso como parte del patrimonio cultural inmaterial del país. Los resultados de esta sistematización pueden ser consultados en el sitio web: www.documentalfolk.com.

\section{El Documental como poética de la realidad}

Existen muchísimas definiciones y discusiones académicas acerca de lo que es o no es documental. El concepto de documental se ha ido tranformando a lo largo del tiempo así como cambiante ha sido la realidad documentada.

Gifreu (1999: p. 56) cita la definición de la World Union of Documentary del año 1948, cuando se consideraba documental "todo método de registrar en celuloide cualquier aspecto de la realidad interpretado bien por la filmación de hechos o por la reconstrucción veraz y justificable, para apelar a la razón o a la emoción, con el propósito de estimular el deseo y ampliar el conocimiento y la comprensión, y plantear sinceramente problemas y soluciones en el campo de la economía, la cultura y las relaciones humanas".

Claramente, como lo explica este autor, el concepto de "registrar en celuloide" ya está superado pues actualmente las tecnologías permiten registrar en numerosos formatos digitales (cámaras profesionales y no profesionales pero también cámaras incorporadas en las tabletas y teléfonos inteligentes), lo cual ha facilitado la crea- 
ción de productos audiovisuales que permiten a las audiencias acceder a sectores de la sociedad con los que, anteriormente, no podían interactuar directamente en su día a día.

Uno de los grandes teóricos sobre el tema documental es el estadounidense Bill Nichols, quien desarrolló un modelo con los distintos modos de representación de los documentales, basado en cuatro modos básicos: el expositivo, el observacional, el interactivo y el reflexivo para, posteriormente, incorporar el poético, el reflexivo y finalmente la modalidad performativa.

Nichols (1991: p. 65) considera que las situaciones y los acontecimientos, las acciones y los asuntos se pueden representar de diferentes maneras y que, debido a que la realidad es cambiante, surgen nuevas modalidades de documental que responden a esos cambios.

Las nuevas modalidades transmiten una nueva perspectiva sobre la realidad. Gradualmente, la naturaleza convencional de este modo de representación se torna cada vez más aparente: la conciencia de las normas y convenciones a las que se adhiere un texto determinado empiezan a empañar la ventana que da a la realidad. Entonces está próximo el momento de la llegada de una nueva modalidad de representación (Nichols, 1991: p. 66).

Es aquí donde el concepto de "representación" es clave, pues nos hace reflexionar sobre cómo nos auto-reflejamos los costarricenses en las producciones documentales, qué valores posicionamos como buenos o malos, qué contenidos escogemos $y$, en resumen, qué historias son las que contamos, por qué lo hacemos y cómo van cambiando esas narrativas y temáticas escogidas.

En ese sentido, el concepto de documental está íntimamente ligado al cómo se representa la realidad, pero un país como Costa Rica tiene muchas realidades y, por lo tanto, esta variedad se verá reflejada por los intereses de los diversos realizadores.

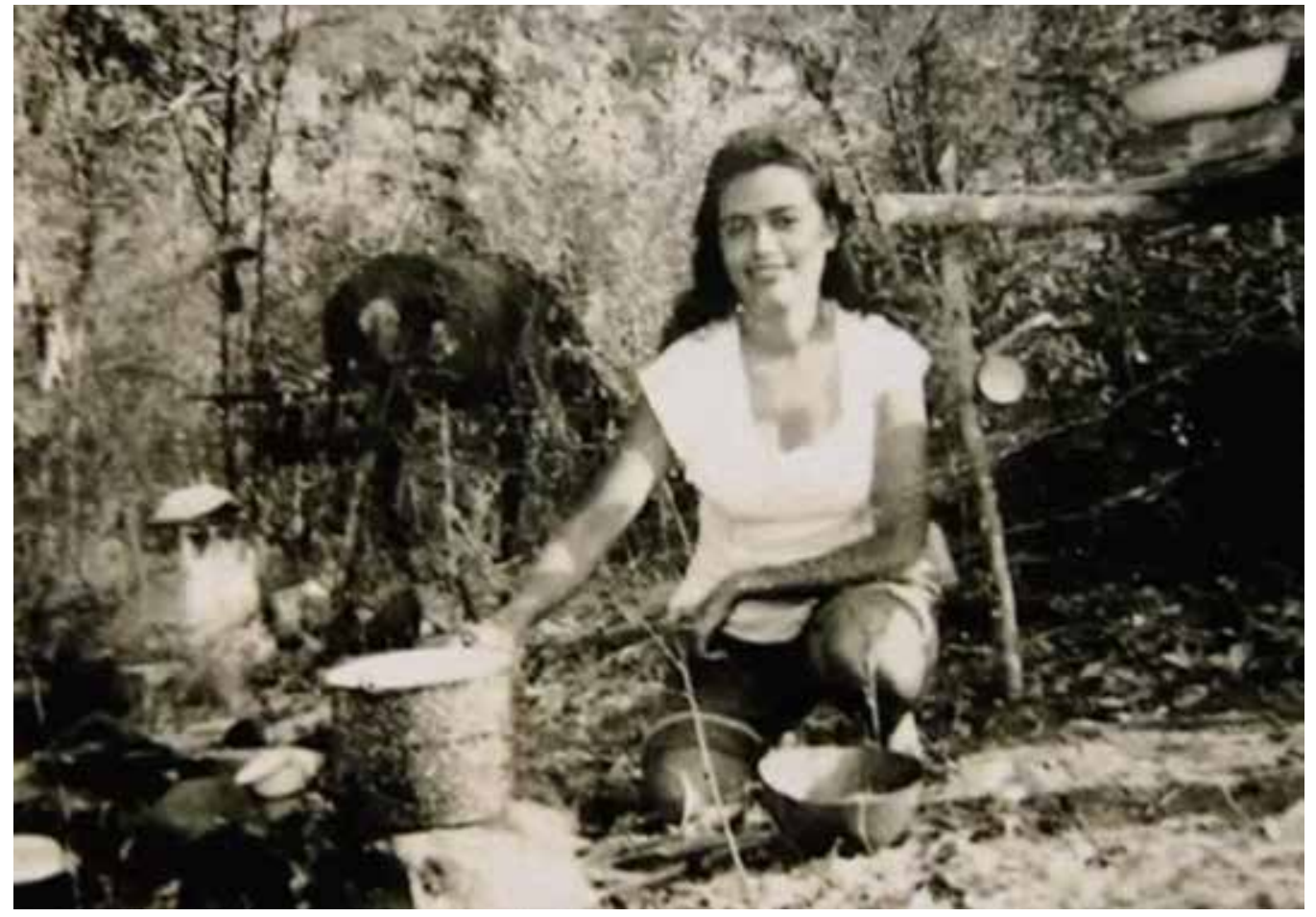

En el documental "Chepita y el mar",

Chepita Lara, una mujer guanacasteca, recuerda su juventud cuando visitaba Playa Iguanita, escenario de sus recuerdos y alegrías (Foto: Gabriela Hernández, Directora). 
Sobre este tema, Grierson (1966: p. 36) considera que "el documental no es más que el tratamiento creativo de la realidad" por lo que, en su criterio, el montaje de secuencias debe incluir no sólo la descripción y el ritmo, sino también el comentario y el diálogo.

El documental realista, con sus calles, ciudades y suburbios pobres, mercados, comercios y fábricas, ha asumido para sí mismo la tarea de hacer poesía donde ningún poeta entró antes y donde las finalidades suficientes para los propósitos del arte no son fácilmente observables. Eso requiere no sólo de gusto, sino también de inspiración, lo que supone, por cierto, un esfuerzo creativo laborioso, profundo en su visión y en su simpatía (Grierson, 1966: p. 37).

En las últimas décadas, con el impacto de internet y las tecnologías digitales surge el concepto de Digital Storytelling (Narrativa o Relato Digital) que complementa muchas de las definiciones previas de documental, pues introduce el concepto de participación ciudadana, ya que las personas con acceso a las tecnologías de la comunicación comienzan a producir sus propios documentales aficionados, aunque no sean profesionales de la producción audiovisual.

Meadows (2003: p. 48) señala sobre el Digital Storytelling que "las pequeñas historias multimedia personales son contadas desde el corazón. Su belleza yace en que este tipo de expresión digital puede ser creada por cualquier persona, en cualquier lugar, sobre cualquier tema y compartido digitalmente por todo el mundo".

Esta corriente se distingue por permitir la realización de productos audiovisuales a prácticamente cualquier ciudadano que desee compartir y visibilizar aspectos de su vida. Junto a esto, renueva las posibilidades y las formas de comunicación con las que la sociedad cuenta. Rodríguez (2007) afirma que la narrativa digital trasciende lo técnico pues, precisamente, al contar una historia de forma subjetiva, inevitablemente se mezclan diversas variables que incluyen el sello personal del autor.

La narrativa digital se puede definir como un objeto virtual capaz de poner en dinámica no solo una dimensión técnica (la utilización de recursos audiovisuales y de las nuevas tecnologías de comunicación), sino también una dimensión estética; esto es, la posibilidad de afectar la experiencia sensible a partir del uso artístico de esas técnicas, con lo que entreteje un tipo peculiar de relato: el relato digital (Rodríguez, 2007: p. 1).

En la misma línea, un texto posterior de Gifreu (2011: p. 2), plantea que "los conceptos de elección y control eran considerados propiedad del documentalista" pero ahora "cuando este poder se otorga al usuario, como en el caso de los medios interactivos, el papel del autor como narrador ( $y$, en consecuencia, el propio punto de vista de la historia) se pone en cuestión o se elimina".

En los documentales tradicionales, la capacidad del autor de influir en el espectador se da por supuesta y se ejerce a través de la filmación y de la estructura discursiva que se articula a partir de la edición y del montaje. Pero, ¿qué pasa cuando esta capacidad se otorga, al menos en parte, al espectador del documental? ¿Qué pasa cuando el espectador ya no es un mero espectador, sino que se convierte en un creador de su experiencia documental? (Gifreu, 2011: p. 2).

En este sentido es aquí donde entra en juego el término de prosumidor, un concepto cuya discusión inició en los años setenta pero que es hasta los primeros años del siglo XXI cuando empieza a posicionarse en los textos académicos y que, para 
nosotros, es básico para este artículo.

Cuando se habla de "prosumidor" se hace referencia a un consumidor de información que, al mismo tiempo, la produce. Es decir, estamos hablando de las nuevas generaciones de consumidores audiovisuales quienes tienen una participación sumamente activa en el proceso de creación, producción y consumo de las narrativas audiovisuales.

El término prosumidor se utiliza para señalar a aquellos usuarios de la red que asumen el rol de canal de comunicación. Tiene su origen en la unión de dos conceptos: productor y consumidor. En un principio no hacía referencia al campo de la tecnología, sino que señalaba a aquel individuo que realizaba actividades para sí mismo, estaba vinculado con la economía: el productor que elabora sus propios productos y los consume, sin necesidad de intermediarios (Sánchez y Contreras , 2012: p. 64).

Estas autoras reconocen un riesgo evidente con este concepto, pues si bien "el uso de estas tecnologías pueden ser una potente herramienta para el cambio, para la visibilización de ideas, opiniones, voces diferentes que se escuchan" son "igualmente potentes para desatar efectos negativos y perjudiciales según la intención de quien las usa" (Sánchez y Contreras, 2012: p. 64) .

Entonces, ¿cómo podemos definir documental? Para nosotros, una de las definiciones que más se acerca a nuestra realidad costarricense es la de Alejandro Cock (2009) y su teoría sobre el "nuevo cine de no ficción", la cual nos da señales de hacia dónde está viajando el documental, tanto en términos de contenido como de forma.

Para Cock, el nuevo cine de no ficción abarca "las heterogéneas prácticas utilizadas hoy, las cuales se mueven en un terreno transfronterizo entre el documental tradicional, la ficción y lo experimental" (Cock, 2009: p. 32).

Si bien Cock hace referencia al término "nuevo cine de no ficción" nosotros preferimos adaptarlo al término "nuevo audiovisual de no ficción", que contempla casi cualquier registro en cualquier formato que documente todas esas diversas realidades que se consideran "no ficción", las cuales abarcan una amplia gama de posibilidades experimentales, como veremos en los ejemplos que se analizan en este artículo.

Es aquí donde deseamos plantear nuestro propio término para la realidad costarricense: el Documental Folk, cuyo nombre, originado en vocablos de los idiomas inglés y alemán (popular), abarca todas esas realidades de la gente que abordan temáticas sobre patrimonio cultural inmaterial y son realizadas tanto por profesionales como por aficionados.

\section{El Documental Folk : su definición y sus dos tipos de realizadores}

Entenderemos como Documental Folk aquellos audiovisuales de no ficción que ayudan a la preservación del patrimonio cultural intangible mediante el registro de tradiciones y expresiones orales, las artes del espectáculo, los usos sociales, rituales y actos festivos, los conocimientos y usos relacionados con la naturaleza y el universo así como las técnicas ancestrales tradicionales.

Estos Documentales Folk se dividen en dos grupos porque tienen dos tipos de realizadores: Documental Folk Tradicional, realizado por profesionales en producción audiovisual; y Nuevo Documental Folk, realizado por personas sin necesariamente tener una formación profesional en este ámbito pero con acceso a las tecnologías que les permiten realizar producciones audiovisuales. 
En el documental "Leyendas urbanas de Costa Rica" (https:// www.youtube.com/ watch?v= 7Fg9HUeUQeQ https://www.youtube. $\mathrm{com} /$ watch? $\mathrm{v}=$ IITID7cf6iM) un grupo de amigos, con edades entre 45 y 55 años, bailan breakdance en la sala de una casa.

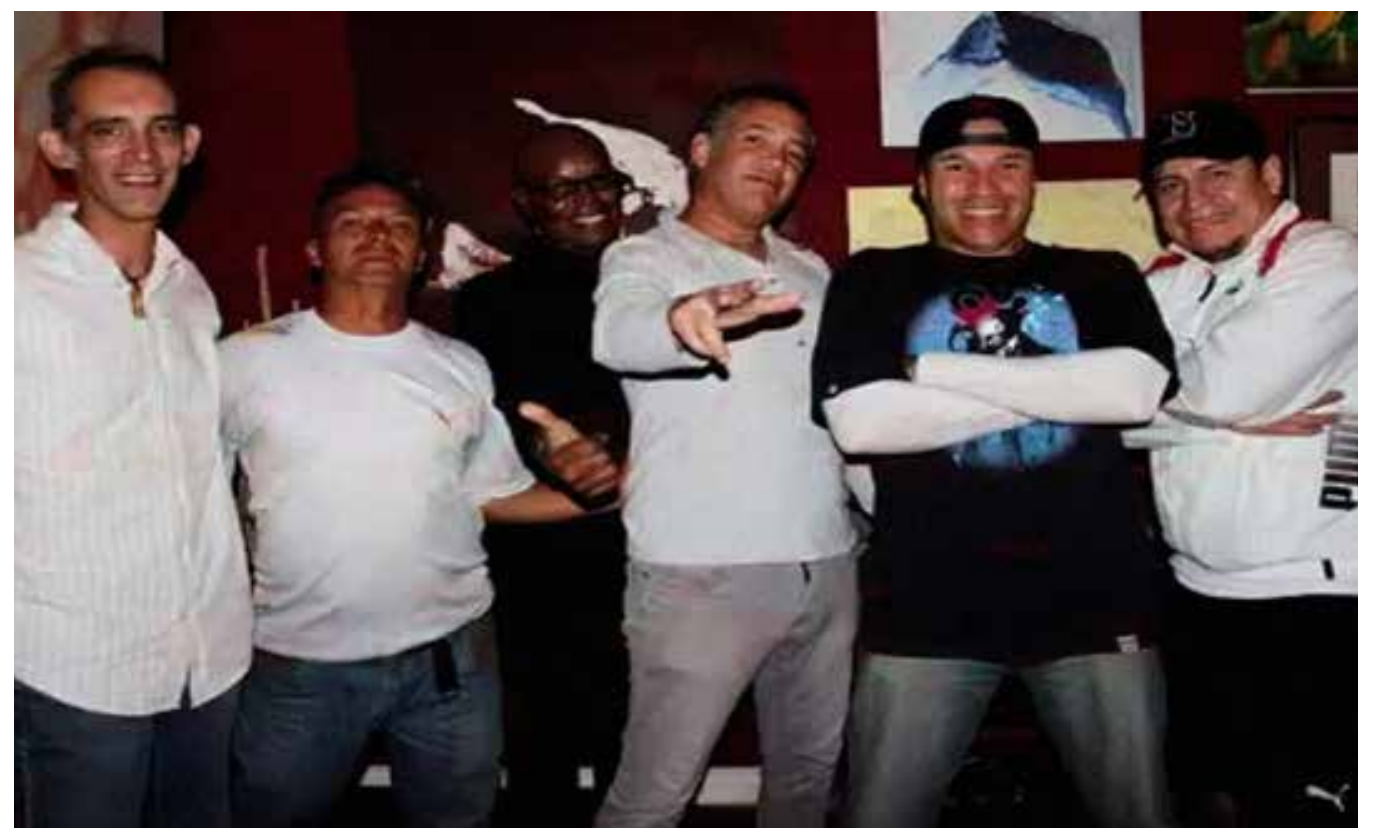

Los Documentales Folk Tradicionales pertenecen a lo que consideramos el mainstream o corriente principal, pues sus realizadores tienen preparación profesional en producción audiovisual y cuentan con acceso a ciertos financiamientos así como al mercadeo y distribución de sus productos. Estos documentales son los que se encuentran archivados en instituciones públicas y privadas que, de algún modo, les han dado esa legitimidad institucional, como documentales.

Por su parte, los Nuevos Documentales Folk son los producidos por personas con o sin preparación profesional en producción audiovisual que documentan con sus cámaras o teléfonos celulares su vida cotidiana.

Ambos tipos de documentales son "Folk" porque abordan las temáticas del patrimonio cultural inmaterial definidas por la UNESCO pero su diferencia radica en la distribución: los primeros pueden ser distribuidos por la televisión local, exhibidos en una sala de cine, comercializados en formatos como DVD o descargas en línea, etc., e incluso pueden contar con estrategias de mercadeo y divulgación. En contraste, los segundos cuentan con un único canal de distribución: Internet.

Con este planteamiento, deseamos abordar la producción de este tipo de documental en Costa Rica y su importante rol como forma de preservar el patrimonio cultural inmaterial del país para que, al mismo tiempo, se convierta en un espejo para mostrar la realidad de una nación que tiene diversos rostros.

\section{Una Costa Rica con múltiples rostros}

En Costa Rica existe una enorme y variada muestra de prácticas y expresiones culturales que, muy pocas veces, han tenido su lugar en los medios de comunicación masiva y, consecuentemente, en la mirada pública de la nación.

Como lo señala el capítulo sexto del XVIII Informe del Estado de la Nación (2012: p. 14) "en el país existe una gran cantidad de agentes culturales independientes (agrupaciones artísticas, empresas productoras, artistas individuales y otros) que cumplen un rol importante en la oferta artística disponible, pese a que enfrentan dificultades para articularse a sistemas de patrocinadores y mecenazgos, así como falta de incentivos". 
Es por ello que nuestro interés personal es poder identificar las temáticas y los enfoques de los ciudadanos que pertenecen a esa "otra Costa Rica", quienes, hasta ahora, han permanecido bastante invisibilizados, pero que, quizás sin percatarse de ello, están documentando y relatando de manera audiovisual la historia reciente de su propio país.

Nos interesa acercarnos al discurso propio de un país que nunca vemos en los anuncios televisivos de Instituto Costarricense de Turismo (ICT) o en los grandes medios de comunicación, donde al pueblo costarricense se le ha recetado una misma serie de símbolos para representar lo patrio y lo cultural. Tal es el caso de las playas, los jóvenes surfeando, la flora y la fauna nacional y, más recientemente, la inclusión de las corridas de toros, entre otros ejemplos.

Si bien se han dado casos de éxito masivo en programas nacionales de televisión producidos localmente, éstos abordan únicamente uno de los muchos rostros del patrimonio inmaterial que posee Costa Rica y lo hacen de una forma comercial que solo muestra algunos aspectos de esa multiplicidad de identidades.

El Documental Folk viene entonces a satisfacer de cierta forma esa hambre de realidad, pues le permite a las personas, con su temática variable, formar parte de la cultura nacional y verse reflejados a sí mismos en la pantalla, cualquiera que ésta sea.

\section{El valor agregado del Documental Folk: la gente}

Al hacer una revisión de los Documentales Folk Tradicionales producidos en los últimos cinco años (2009-2013) y archivados en las instituciones ya mencionadas, se observa que sus temáticas coinciden con las que plantea la UNESCO en relación con el patrimonio cultural inmaterial.

Estos temas van desde técnicas ancestrales, como las practicadas por los indígenas costarricenses; pasando por actos rituales, como la peregrinación hacia la Basílica de los Ángeles cada 2 de agosto; artes del espectáculo, como los mariachis; hasta temáticas innovadoras, como la de un joven que practica el satanismo como su modo de vida.

Sin embargo, todos comparten un denominador común: la espontaneidad del costarricense cuyas expresiones orales y no verbales reflejan una identidad que solo se puede ver cuando cada uno de los protagonistas de estos documentales comienza a hablar para relatar su propia vida pues, tal y como lo plantea la UNESCO, el idioma es uno de los vehículos del patrimonio cultural inmaterial.

Es ahí, en el lenguaje, en la forma de expresarse de la gente común, donde, en nuestro criterio, radica esa riqueza del patrimonio cultural inmaterial de Costa Rica pues las diversas formas de expresión oral son un espejo que refleja esa enorme variedad cultural sobre la que está construida nuestra nación.

En el caso del Nuevo Documental Folk, las temáticas se acercan más a prácticas populares, como los actos musicales o los bailes tradicionales, las cuales pueden ser desempeñadas por personas de cualquier clase social

Estos documentales se distancian de las temáticas institucionales o pedagógicas que sí contempla el Documental Folk Tradicional, como las prácticas indígenas o los documentales sobre temas históricos, y se enfocan más en las realidades contemporáneas de las zonas urbanas, las cuales poseen la mayor densidad demográfica del país.

La relación de las comunidades entre sí y la creación de grupos populares van de la mano con la creación de estos documentales aficionados. La identificación de un grupo perteneciente a una cultura específica permite que exista un mayor entusiasmo para la realización de estos documentales. 
Por ejemplo, los "punks" hacen documentales sobre "punks" y le piden ayuda a otros "punks". Los "skaters" hacen documentales sobre "skaters" y le piden ayuda a otros "skaters". Los palmareños hacen un documental sobre Palmares y le piden ayuda a la Municipalidad de Palmares, etc. No obstante, una característica importante del Nuevo Documental Folk es el anonimato de muchos de sus realizadores, pues pareciera importar más la difusión de la colectividad que el reconocimiento individual (Ver más detalles de ambas categorías en www.documentalfolk.com).

\section{Un país con gente que reclama su derecho a la imagen}

En el presente artículo, abordamos dos territorios del espectro del documental costarricense: el Documental Folk Tradicional y el Nuevo Documental Folk. Luego de analizar los contenidos de ambos grupos, una de las primeras conclusiones a la que llegamos es que, en las temáticas que abordan, ambos tipos de documental presentan más similitudes que diferencias.

En ambos grupos los temas coinciden con las categorías de patrimonio cultural inmaterial que establece la UNESCO. Sin embargo, cabe destacar que en el caso de los Nuevos Documentales Folk se presenta una menor cantidad de producciones en las categorías de técnicas ancestrales tradicionales y conocimientos y usos relacionados con la naturaleza y el universo, las cuales son mucho más abordadas por el Documental Folk Tradicional, pero hay una mayor producción en la categoría abierta, donde se abordan expresiones culturales contemporáneas que se practican más en zonas urbanas como el parkour o el uso de software libre.

En ambos grupos, todos los documentales tienen un denominador común que son sus protagonistas, quienes aportan sus testimonios en primera persona, lo que le da una importancia vital a este tipo de documentales pues el idioma se convierte en el vehículo para expresar y conservar el patrimonio cultural inmaterial.

Son esos testimonios de la gente común lo que nos ha permitido tener un redescubrimiento de nuestra identidad nacional: la vigente, la pasada $y$, en algunos casos, la que está por venir.

La forma de construir las frases, la riqueza de las palabras, el tratamiento distante pero al mismo tiempo íntimo, el humor y el doble sentido forma parte de esa manera de ser del costarricense que la cámara hace tangible.

Es por ello que creemos que los "ticos", al menos cuando se ponen frente a una cámara, muestran una alegría innata que se expresa a través de su lenguaje físico y verbal así como en su actitud emocional, aunque la temática del documental en el que aparecen no corresponda exactamente a un tema alegre.

Ahora bien, aunque encontramos importantes similitudes en las temáticas abordadas, ¿sobre qué aspecto podemos evidenciar que el Documental Folk Tradicional y el Nuevo Documental Folk son corrientes distintas? La respuesta está, por un lado, en los canales de distribución para cada uno, y, por otro, en la intención del realizador.

Con respecto a la distribución, hemos concluido que la producción de temáticas folk es sumamente abundante, pero poco conocida. Entre los años 2009 y 2013 el Centro de Cine recibió 155 documentales para concursar en las distintas muestras y festivales de cine. De estos 155 documentales, 110 eran Documentales Folk, es decir, un $71 \%$. De los documentales ganadores de estas muestras o festivales, el 95\% abordó temáticas folk.

Entonces, ¿por qué no se visibilizan tanto en el medio como sí lo hacen las ficciones? La dificultad que ha encontrado el formato documental en el acceso a salas de cine para alcanzar públicos masivos nos confirma que es la distribución el factor que 
limita el impacto que un audiovisual puede tener.

Con respecto a la intención del realizador, creemos que la posibilidad de crear un documental para acceder a distintos públicos es algo que genera diferencias importantes a la hora de producir estos audiovisuales.

El documentalista folk tradicional trabaja para mostrar sus proyectos en presentaciones públicas, en festivales, en cines, en canales de distribución institucionalizados (como Festival Internacional de Cine Costa Rica Paz con la Tierra o el fondo DocTV). En contraste, el nuevo documentalista folk trabaja, muchas veces desde el anonimato, por la necesidad de verse reflejado a sí mismo o a su grupo social en una pantalla o bien por la exigua gratificación de las reproducciones en Youtube o bien como una simple forma de entretenimiento, como lo confirmaron las entrevistas que realizamos a diversos realizadores.

Otra de las diferencias es que el documentalista folk tradicional inevitablemente es un intermediario entre el espectador y la realidad que quiere narrar en su documental, mientras que para el nuevo documentalista folk ese nivel de intermediación es mucho menor pues -si bien existe- él está contando en primera persona su propia realidad y no la realidad de los otros.

En ambas categorías, creemos que la mayor riqueza está en la combinación de los aspectos sensoriales con los intelectuales que se mezclan en los documentales folk. Las representaciones de una nigüenta en la sala de una casa, el color de las paredes, dientes que le faltan al protagonista del documental, perros que ladran, son ejemplos de los diversos aspectos que confluyen en el lenguaje empleado en los documentales folk.

Una vez que hemos recorrido todos estos aspectos del documental folk, tanto tradicional como nuevo, debemos preguntarnos nuevamente ¿qué queremos lograr como sociedad a partir del registro del patrimonio cultural inmaterial? ¿De qué sirve la memoria documentada de nuestra cultura? ¿Cómo queremos utilizar este conocimiento que distintos realizadores han registrado?

Con el tiempo esto lo deberemos responder juntos como sociedad, pero creemos que este artículo es un pequeño primer paso en la sistematización del documental en Costa Rica pues pensamos que esta clasificación debe responder a la realidad nacional, donde no solo se deben tomar en cuenta aspectos técnicos o temáticos sino también aspectos del patrimonio cultural inmaterial que unifiquen la metodo-

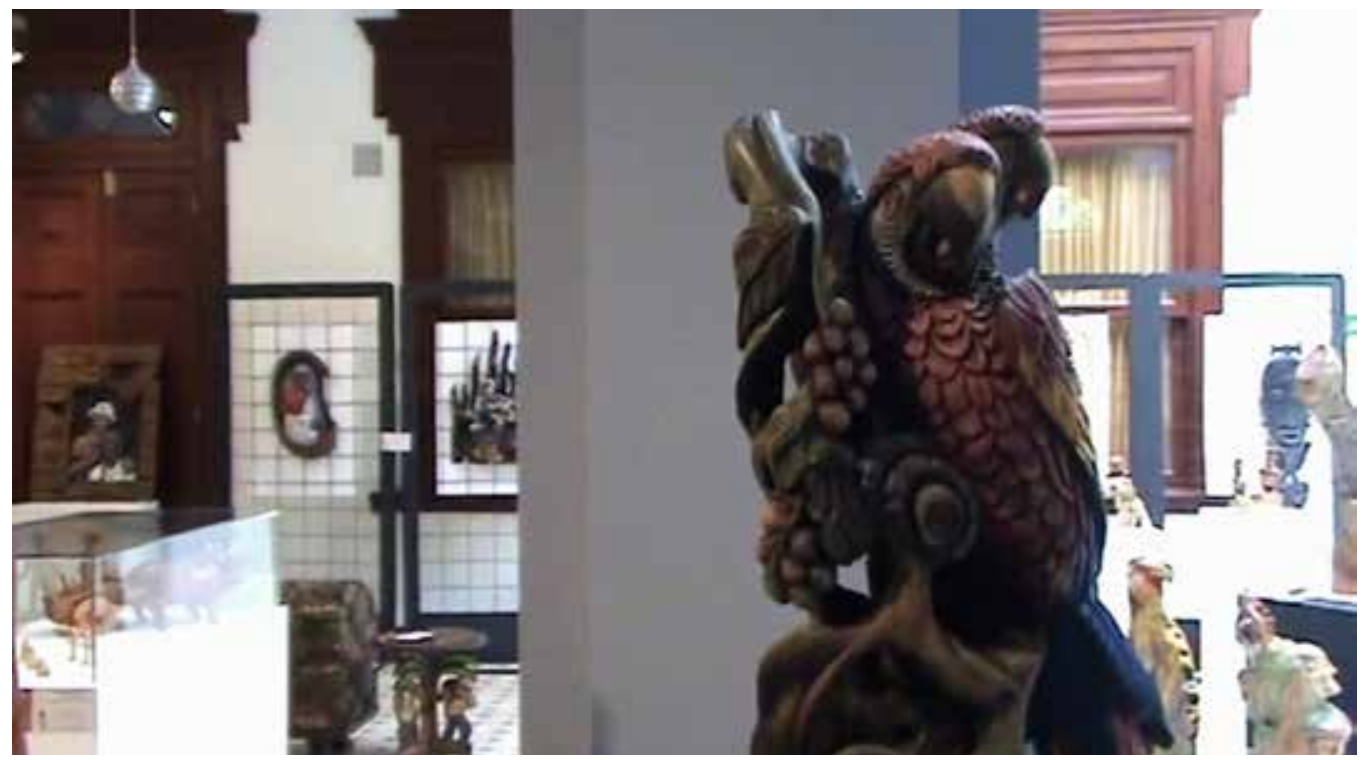

En el documental "Exhibición artesanía en madera" (https:// www.youtube.com/ watch?v=

Bn0oPUBp5Qw) se observa un un cuadro hecho con la técnica conocida como pirograbado sobre un personaje llamado Cuca. Se trata de un vídeo elaborado por el Centro de Patrimonio del Ministerio de Cultura y Juventud. 
logía de clasificación y archivo.

Por otro lado creemos que junto a la sistematización y archivo se debe trabajar en la divulgación, pues la memoria no solo debe ser guardada, sino que debe ser conocida, ya que la interpretación que hacen los prosumidores de estos documentales les aporta una importante significación pues se trata de un texto multimodal, como señalan Kress y Van Leeuwen $(2001,3)$, quienes articulan el significante y el significado.

"En la comunicación contemporánea donde la lingüística tradicional tenía un lenguaje definido como un sistema que funciona a través de la doble articulación, donde un mensaje era una articulación entre significante y significado, nosotros vemos textos multimodales como constructores de sentido en múltiples articulaciones", (Kress y Van Leeuwen, 2011: p. 2).

El planteamiento anterior nos permite entender comunicación no solamente desde el punto de vista de los productores, sino que comprende también el área de la interpretación por parte del consumidor, que ahora es un prosumidor. Es decir, la comunicación contemporánea solo se da si existe una articulación pero también una interpretación del mensaje.

Así que, retomando la pregunta de Gifreu: ¿Qué pasa cuando el espectador ya no es un mero espectador, sino que se convierte en un creador de su experiencia documental?, creemos que ya estamos comenzando a ver lo primeros elementos para construir esa respuesta: un campo de producción audiovisual más heterogéneo, donde se reflejan los diversos estratos sociales de un país con muchos rostros y donde el espectador se verá cada vez más involucrado de forma participativa para incluir sus códigos y sus aportes comunicativos.

Creemos que este es el camino para perder el miedo a mirarse en el espejo y para que los costarricenses comiencen a reclamar su derecho a la comunicación: el derecho a que su imagen también se pueda mirar en el "gran espejo país" de la producción audiovisual de Costa Rica.

\section{Bibliografía}

Cock, A (2009). Aproximación al documental y al cine de no ficción. Recuperado de: http://www.agifreu.com/v_angles/com_audiovisual/documental/aproximacion_documental.pdf

Costa Rica achieves a Happy Planet Index Score of 64.0 and ranks \# 1 of all the countries analyzed. (2014). En Happy Planet Index. Recuperado de http://www. happyplanetindex.org/countries/costa-rica/

Estado de la Nación (2012). XVIII Informe del Estado de la Nación (2012). Recuperado de: http://www.estadonacion.or.cr/

Gifreu, A. (1999). El documental interactivo. Una propuesta de modelo de análisis. Barcelona. Department de Comunicació. Universitat Pompeu Fabra.

Gifreu, A. (2011). El documental multimedia interactivo como discurso de la no ficción interactiva. Por una propuesta de definición y categorización del nuevo género emergente. En Hipertext.net. Anuario Académico sobre Documentación Digital y Comunicación Interactiva. No. 9. Recuperado de: http://www.upf.edu/ hipertextnet/numero-9/documental-multimedia.html

Grierson, J. (1966). Grierson on Documentary. Berkeley: University of California Press.

Kress, G. y van Leeuwent, T. (2001). Multimodal discourse. The modes and media of contemporary communication, Londres, Arnold. 
Meadows, S. (2003). Pause and Effect. The art of interactive narrative. Indianapolis: New Riders.

Nichols, B. (1991). La representación de la realidad: Cuestiones y Conceptos sobre el Documental. Barcelona: Paidós.

Patrimonio Inmaterial (2014). En UNESCO. Recuperado de http://www.unesco.org/ new/es/mexico/work-areas/culture/intangible-heritage/

Rodríguez, J.A. (2007). Teoría, práctica y enseñanza del hipertexto de ficción: el relato digital. En Pontificia Universidad Javeriana. Recuperado de http://www. javeriana.edu.co/relato_digital/index.htm

Sánchez J.; Contreras P. (2012). Producción y consumo: empoderando a la ciudadanía 3.0. En Revista Icono 14 (Comunicación y Tecnologías Emergentes). Vol. 10. (No. 3). pp. 62-84. doi: 10.7195/ri14.v10i3.210 
Revista Herencia Vol. 29 (1), 2016 